\title{
THE
}

\section{Converting Asset Holdings into Livelihood: An Empirical Study on the Role of Household Agency in South Africa}

Bret Anderson

University of Rhode Island, bret_anderson@mail.uri.edu

Follow this and additional works at: https://digitalcommons.uri.edu/ecn_facpubs

Terms of Use

All rights reserved under copyright.

\section{Citation/Publisher Attribution}

Anderson, Bret. 2012. "Converting Asset Holdings into Livelihood: An Empirical Study on the Role of Household Agency in South Africa." World Development 40, no. 7 (July): 1394-1406. http://dx.doi.org/ 10.1016/j.worlddev.2012.03.015

Available at: http://dx.doi.org/10.1016/j.worlddev.2012.03.015. 
Converting Asset Holdings into Livelihood: An Empirical Study on the Role of Household Agency in South Africa

February 21, 2012

Bret Anderson

University of Rhode Island

bret@uri.edu 


\begin{abstract}
This paper analyzes the complexities of converting assets into livelihood and the role that agency constraints play. Drawing inspiration from the capabilities approach and using household data from South Africa, linkages between assets and agency are identified by decomposing asset endowments' impact on future livelihood. By employing a method of path analysis akin to early heritability of traits studies, theoretical asset-based studies of chronic poverty are bridged with capabilities literatures. The interaction between assets and agency is shown to be as important as asset-to-asset complementarities. The results have wide ranging policy implications.
\end{abstract}

Keywords: poverty, capabilities, assets, South Africa, KwaZulu-Natal 


\section{INTRODUCTION}

To understand the transmission of poverty, flow variables like income or consumption have only limited use. Asset stocks are more informative since they implicitly contain additional information on the future livelihood prospects of the economically disadvantaged. Asset endowments provide a cushion against income shocks, are a source of future income and consumption streams, and are generally indicative of future economic well-being. The inherent qualities of asset stocks thus offer a more predictive measurement of poverty than current income or consumption flows (Carter and Barrett, 2006). It follows that a central tenet of an asset-based view of poverty is that time is an ally of the poor so long as asset levels are sufficiently high; but what constitutes sufficiently high is not readily known. For example, in South Africa's most populated province of KwaZulu-Natal, time has not been an ally to many of the poor even when asset stocks are relatively high. During the eleven-year period of 1993 to 2004, approximately half $(51 \%)$ of the 750 households sampled had, on average, been living on less than two U.S. dollars per day. Of that half, $21 \%$ were in the upper half of the entire distribution of initial asset endowments. ${ }^{1}$ The take away message is that for some households, the critical minimum level appears to be higher than for others.

As with any measure of poverty, tradeoffs exist. Assets typically do not aggregate easily and are thus often reduced to an index or one choice asset to draw out the dynamics over time. Indeed there is a growing literature of livelihood mapping that attempts to map opulence wellbeing from asset space into a more policy familiar income or consumption space (for example see Adato et. al., 2006; Carter \& May, 2001). Yet there exists a stark disconnect between assetbased approaches and the more multi-dimensional human development/capabilities (HD/C) 
perspectives of poverty measurement that view development in terms of expanding substantive freedoms rather than simply as commodity availability. Sen's pioneering work on capabilities describes how the commodity requirements of established patterns of behavior may vary between personal, social, and environmental factors (Sen, 1999a, 1999b; Robeyns, 2007; Alkire and Deneulin, 2009). The expanded capabilities view in combination with the South African experience suggests that asset levels alone are not enough to clearly identify vulnerable households.

Regarding theoretical work on critical minimum asset levels, there has been some work on the role of intrinsic ability as a determinant of poverty trap thresholds (Carter and Ikegami, 2007); however, what intrinsic ability may encompass has been understudied within the assets framework. The question then is how to empirically identify the fundamental linkages between particular asset holdings and intrinsic ability to better understand how assets can benefit the poor. This paper serves as a constructive critique of asset-based poverty studies by incorporating useful insights from the human development and capabilities approaches in an applied manner. The capabilities approach provides one such way of expanding upon intrinsic ability by way of household agencies. Agency is the ability to pursue goals that one values and has reason to value (Alkire and Deneulin, 2009). An agent is someone who acts and brings about change (Sen, 1999a:19). It should be noted how agency is different from capabilities and functionings. Functionings are the various things a person may value doing or being (Sen, 1999a: 75). Capabilities refer to the various functionings (beings and doings) that a person can achieve and are thus a vector of functionings reflecting the person's freedom to lead one type of life or another (ibid). Deprivation in household agency can therefore be seen as a potential deprivation of capabilities. 
Different personal, social, and environmental situations potentially impact an individual's or household's degree of agency with respect to converting asset holdings into economic livelihood or well-being ${ }^{2}$. This study draws out how household agencies interact with particular asset endowments and thus impact the conversion process of assets into economic livelihood. If borne out by empirical evidence, poverty reduction strategies could be made more effective by incorporating knowledge of how different agency variables interact with particular assets (such as human, productive, or financial capital) to either facilitate or constrain the process of converting those assets into livelihood.

Following a technique used in the heritability of genetic traits literature and employed by Bowles and Gintis (2002), this paper decomposes the impact of initial asset endowment on future livelihood into direct and indirect mechanisms. A direct conversion of asset endowments into future livelihood simply includes consumption of the asset or the direct use of it to produce incomes. The more complex indirect conversions are of two forms: via asset-to-asset complementarities and via the interaction of assets and household agency variables. Some examples of variables that possibly interact with assets and signal heterogeneity in agency may include social networks, trust, or time commitments stemming from care and/or subsistence activities, among others. Sections three and four have greater detail regarding the choice of methods and variables specific to this study.

The results suggest that although direct effects and asset-to-asset complementarities are important to the conversion process at the household level in South Africa's KwaZulu-Natal province, the degree of time deprivation from subsistence activities may condition poverty trap thresholds to a greater extent for households with higher levels of educated laborers, capital, and access to agricultural land. The results likely reflect the larger realities of macroeconomic 
conditions and underemployment in South Africa in which relatively well-resourced groups have the wherewithal to face binding micro-constraints, whereas households with few resources cannot overcome the constraints imposed by poor macroeconomic conditions. In terms of poverty policy, opportunities at the macroeconomic level and household agency at the microeconomic level both play an important role.

This study contributes to the prior literature in three primary ways. First, it extends and adds empirical robustness to prior theoretical work linking a latent concept of intrinsic ability with household-specific poverty trap thresholds. Second, it bridges the quantitative work on poverty traps with qualitative insights from the HD/C literature by identifying which particular asset holdings are associated with different household capability constraints via household agency variables. Lastly, it brings awareness to policy makers that though asset levels alone may be a necessary condition for poverty alleviation, knowledge of the sufficient condition of possessing the ability to convert assets into livelihood is equally important.

The rest of the paper is organized as follows. Section two outlines a bridged asset basedHD/C framework with particular focus on the relationship between household agency and poverty trap thresholds. Section three describes the empirical decomposition of asset endowments' impact on future livelihood into direct and indirect effects in an attempt to identify which asset holdings are associated with particular household agency variables. Section four describes the household data from KwaZulu-Natal and is followed by a discussion of the results, limitations, and possible extensions. 


\section{THEORETICAL FOUNDATIONS: ASSET HOLDINGS, INTRINSIC ABILITY, AND HOUSEHOLD AGENCY}

One way of making poverty measurements more forward-looking and predictive than observed income or consumption flows is to follow the now prominent framework of asset-based poverty measures. Asset endowments provide a cushion against income shocks, are a source of future income and consumption streams, and are generally indicative of future economic wellbeing (Carter and Barrett, 2006; Lerman and McKernan, 2008). This section begins by outlining some of the basic features of the assets view with particular emphasis on the empirical and theoretical treatments of poverty trap thresholds ${ }^{3}$. Although the asset-based approach has wellgrounded micro-foundations, it often lacks the qualitative dimensionalities of $\mathrm{HD} / \mathrm{C}$ perspectives

of poverty. Consequently, after laying out the theoretical aspects of poverty trap thresholds, the discussion turns toward inclusion of qualitative aspects from the $\mathrm{HD} / \mathrm{C}$ literature in order to diagnose how structural characteristics that lead to household agency and empowerment play an instrumental role in converting particular asset holdings into economic livelihood.

\section{(a) Asset-Based Studies and Empirical Observations of Critical Thresholds}

In a now seminal paper titled, "The Economics of Poverty Traps and Persistent Poverty: An Asset-Based Approach", Carter and Barrett (2006) outline a microeconomic framework capable of explaining how households or individuals can persist over time at higher or lower welfare states (see also Barrett (2008) for a concise overview). The authors describe a situation in which if there are locally increasing returns to scale of asset holdings, then multiple equilibria 
may exist in which accumulation behavior bifurcates. Implicit in their discussion of multiple equilibria is a discussion of critical thresholds that define the boundaries between equilibria. A poverty trap threshold is defined as a critical minimum stock of assets that are needed for an individual or household to ensure increases in economic livelihood into the future. With few exceptions, the challenge within this literature to date has been not just to confirm the existence, but to identify how individual or group abilities condition these critical thresholds. This is complicated by the fact that thresholds, if they exist, are unobservable at the individual level.

Figure one is adapted from Carter and Barrett (2006) and illustrates a basic situation in which there are two production activities available to a particular household, $\left\llcorner_{1}\right.$ and $L_{2}$. Activity $\mathcal{L}_{2}$ requires a higher level of fixed costs, but can ultimately generate a higher level of livelihood or welfare - measured on the vertical axis. For illustrative simplicity, one could interpret $\mathcal{L}_{1}$ as subsistence, in home production process of generating livelihood, whereas $L_{2}$ might be formal labor in which the higher fixed costs stem from the opportunity cost of being outside the home. For now, assume assets are multi-dimensional and can be easily aggregated into one bundle, measured on the horizontal axis. The asset endowment level $\mathrm{A}^{\mathrm{s}}$ identifies the level of assets in which it would be optimal to switch from process $\mathcal{L}_{1}$ to $\mathcal{L}_{2}$. Two equilibria emerge: a lower $\left(\mathrm{L}_{\mathrm{L}}\right.$, $\left.A_{L}\right)$ and higher welfare state $\left(\mathrm{L}_{H}, \mathrm{~A}_{\mathrm{H}}\right)$. The two equilibria correspond to where the marginal return on assets is equal across the two production processes. That is, the forward looking household in this simple model is just indifferent between the two processes. If the household were endowed with assets below $\mathrm{A}^{\mathrm{s}}$, but above $\mathrm{A}_{\mathrm{L}}$, the out of equilibrium dynamics would suggest a decumulation of assets and the household could be described as moving toward a poverty trap at the lower equilibrium (provided it is below the poverty line).

[INSERT FIGURE 1 HERE] 
With regard to credit access, a forward-looking household would simply crossover the $\mathrm{A}^{\mathrm{s}}$ threshold provided there are well-functioning credit markets and no impediments to autonomous saving strategies. However, in the development context this would commonly be considered the exception rather than the rule. Impediments to process switching thus lead Carter and Barrett to conclude that as long as a household is "not too far away" from $\mathrm{A}^{\mathrm{s}}$ then switching toward a strategy that moves them toward the upper equilibrium might be expected (see also (Loury, 1981; Banerejee and Newman, 1993; Galor and Zeira, 1993; Mookherjee and Ray, 2002)). The level of what is "not too far away" is what Carter and Barrett term the Micawber threshold, A* in figure one, and what has generally been referred to as the household's poverty trap threshold. It is worth noting that a study of household-specific poverty trap thresholds is subtly different from traditional studies of poverty traps and observed persistent poverty. Studies of the determinants of poverty traps (rather than poverty trap thresholds) focus on defining chronic poverty. Once an acceptable concept of chronic poverty is found, then characterizations can be made regarding the existence or determinants of poverty traps. Often this includes using lagged values of the dependent income or welfare measures as regressors, which requires an assumption of past dynamics continuing into the future. A study of poverty trap thresholds, however, is fundamentally different in that household-specific thresholds are generally unobserved - no matter how they are defined. If the multiple equilibria model accurately describes a household's behavior, at any given time researchers are likely to observe households around a stable equilibrium rather than near a dynamically unstable threshold point. Therefore, relatively few observations in a sample would be near the threshold (Carter and Barrett, 2006). Additionally, an individual or collective household is not likely to know where their threshold level lies. It is difficult for one to know that if their stock of assets fell below a certain level, recovery would be 
difficult or impossible in the medium to long run. Thus, direct observation of critical thresholds is unlikely and requires an indirect, and somewhat novel, approach. The benefit of this type of study is that it is more forward looking than studies of observed, past persistent poverty. In essence, a threshold study is structured to identify those that are more vulnerable to future uncertainties.

Turning now to empirical analyses of the existence of poverty trap thresholds, pioneering studies include: Lybbert et al. (2004), Adato et al. (2006), Barrett et al. (2006), and Santos and Barrett (2006). All four studies do find evidence of the existence of poverty trap thresholds in a framework similar to the one presented above, but typically rely on one sample-wide threshold, rather than a household-specific threshold. This is often justified in samples where there is one predominant asset or employment choice. When assets and occupational choices increase in number the identification of a sample-wide threshold is more difficult. More importantly, the role of individual or group ability in determining critical asset stocks remains understudied. ${ }^{4}$

Concerning authors in the more traditional poverty trap literature, McKenzie and Woodruff (2003), Jalan and Ravallion (2000), Loshkin and Ravallion (2004), and Antman and McKenzie (2005) all present mixed evidence of the existence of poverty traps; but as described above, these studies investigate fundamentally different dynamics than studies of thresholds. To date, there have been few, if any, studies of how individual agencies determine thresholds in a world of complex asset holdings. Progress has been made however in theoretical treatments of how intrinsic ability and critical thresholds, in which the next section addresses. 


\section{(b) Intrinsic Ability as a Theoretical Determinant of Critical Thresholds}

The complexities involved with observing heterogeneous thresholds suggest two types of responses: expansion of theoretical treatments via simulations or searches for empirical clues rather than direct observation. This paper is concerned with the latter, but first discusses lessons emerging from theoretical simulations.

Carter and Ikegami (2007) take a first step in bringing the capabilities discussion to the forefront of the theoretical literature through dynamic programming simulations. The agents in their simulation are endowed with a given amount of ability with certain probability. Their results suggest that critical thresholds are a negative function of intrinsic ability at the individual level. Although this study is instrumental in initiating the idea of a household specific critical threshold, it lacks any empirical discussion of what intrinsic ability might encompass. What household characteristics make up the ability to convert productive assets into livelihood? Among others, social networks, intra-household structure, and time constraints are all potential factors that can facilitate (or constrain) the attainment of higher welfare with a given endowment

of assets. Returning to the South Africa example illustrated at the outset, a number of households had relatively high levels of assets, but were not observed to be successful in converting them into livelihood. Carter and Ikegami's theoretical study on intrinsic ability is pioneering in that it provides a natural entry point for $\mathrm{HD} / \mathrm{C}$ approach to further explore the role of intrinsic ability through the lens of household agency. 


\section{(c) Observing Intrinsic Ability as Agency}

Conceding that direct observation of household-specific poverty trap thresholds is not feasible leads to a search for more tangible clues rather than direct observation. This requires first taking on the question of what might intrinsic ability encompass in any observable manner. Given that both strands of the development literature often claim heritage to the broad work of Sen, it provides a natural bridge between an HD/C perspective and Carter and Ikegami's (2007) theoretical study on the role of a latent concept labeled intrinsic ability. Thus, a workable definition of intrinsic ability lies within the capability literature's treatment of agency.

Agency is the ability to pursue goals that one values and has reason to value (Alkire and Deneulin, 2009). As was laid out in section one, agency is different from the outcomes of capabilities and functionings. Functionings are the various things a person may value doing or being; whereas capabilities refer to the various functionings (beings and doings) that a person can achieve and are thus a vector of functionings reflecting the person's freedom to lead one type of life or another. Deprivation in household agency can therefore be seen as a potential deprivation of capabilities. Nambiar (2011) similarly suggests that the interaction between the agency and well-being of individuals is defined by the social constraints they face. By observing the different factors that potentially impact an individual's or household's degree of agency one can begin to uncover how particular asset endowments translate into economic livelihood. The determinants of this conversion process thus signal potential idiosyncrasies in household-specific thresholds.

It should be noted that a clear line between assets, capabilities, and agency variables is a difficult one to draw. The primary challenge is that resources such as financial assets, land, social 
capital or others play both an instrumental (means) and constitutive (ends) role with respect to one's ultimate well-being (Sen, 1999a). In a particular reference to the agency of human beings, Sen (1997) recognizes that the concept of human capital (augmenting one's production possibilities through skill, knowledge, or effort) also fits within a broader concept of human capability because of the dual roles played by human capital. Clark (2005) continues the point further by suggesting that the capability approach overlaps with both utility and resource-based concepts of well-being, citing participatory field research in South Africa. In the model presented in the next section, the line between asset holdings and agency variables is presented as distinct for clarity and illustrative purposes, yet the reader is encouraged to interpret asset and agency variables as they see fit, as the categorical distinction does not influence the outcomes of the econometric analysis. However, the prescriptive interpretations of the results may differ given the relative weights one places on the constitutive and instrumental roles of different resources. In an attempt to further compare the two strands of literature, Hulme and McKay (2007) make three observations regarding the two perspectives. First, is that a narrow range of assets is typically the focal point in an assets only framework. A narrow range of assets is typically used on the grounds that assets are correlated and standard regressions have inflated standard errors when all assets are included. This leads to aggregation methods such as using factor or principle component analysis to achieve a reduction in the dimensionality. However, knowledge of personal, social, and environmental heterogeneities across assets has important policy implications, so dimensionality reduction may be counter-productive. Focusing on how different measures of agency are linked with particular asset holdings sheds further light on factors traditionally considered external. Second, there is typically very little discussion of factors that affect the returns to assets, however assets are defined. Assets at the household, meso, or macro 
level may exhibit locally increasing returns to scale or different levels of functioning as compared to other environments (Barrett, 2006). If policy is to center on asset transfers, then knowledge of an environment of successful conversion into livelihood is important. A third criticism levied on asset-based studies is that income and monetary metrics still have a central role in asset-based poverty measures and they may not be reflective of the true state of development. The current analysis addresses these gaps in a number of ways. I first begin with a broad brush stroke of assets to address the first divide. Five dimensions of assets are used: educated labor, uneducated labor, agricultural land, physical/financial capital, and unearned transfer sources. The empirical model presented in section three can include many assets without the limitations typically imposed by high collinearities among them. This framework also explicitly addresses the second divide by discussing what factors might affect returns to assets, namely how agency variables interact with assets.

This study is culpable with respect to the latter challenge of relying on monetary measures of well-being. However, a back of the envelope calculation of a more participatory index for South Africa that includes four of seven self-reported deprivation components for which data were readily available has a correlation of .78 with this paper's welfare measure, livelihood. One could make the argument that, as a practical matter, the welfare measure is at least highly correlated with identified and participation-defined development dimensions. ${ }^{5}$ At the risk of the discussion of variables getting ahead of their introduction, the use of livelihood (opulence) as an outcome measure admittedly captures only one dimension of the broader concept of well-being. Other dimensions or multi-dimensional measures of well-being might be more suitable and less ambiguous when describing the conversion process of assets into general well-being. Martinetti (2006) provides an overview of the critiques levied upon the economics 
discipline's general disregard for the issues of complexity and vagueness that intrinsically characterize the concepts of well-being and suggests alternative methods that better address the ambiguity, such as fuzzy set theory (FST). Though the search for suitable treatments of wellbeing is arguably a high priority, it remains out of the scope of this study, in which the aim is to provide a constructive critique of prior asset-based studies and the affinity for livelihood mapping strategies by extending the existing framework outlined in section two. A central reason for specifically preserving livelihood in its original form is to retain it's perceived appeal as a more policy friendly measure in many circles. This policy friendly nature stems from its easy inclusion into traditional measures of poverty such as the Foster-Greer-Thorbecke (1984) class of measures. If the reader will permit, I'll borrow a line from Sen (1999b:4) and suggest that the purpose of this analysis is not the search for such a magic measure. It is more to clarify the roles and limitations of different concepts of interest and to fill in what may well be important gaps in the conceptual apparatus of interest assessment. Sections three and four will have more to discuss regarding the choice of modeling and outcome specification, which the analysis turns to next.

\section{ECONOMETRIC MODEL}

To address the question of which particular assets are empirically linked with particular agency measures, the correlation between the $\mathrm{j}^{\text {th }}$ asset endowment and future livelihood can be decomposed into direct and indirect effects. That is to say, the correlation between a household's possession of a particular asset, say its endowment of productive capital, with an observed future welfare level can be broken down into the proportion of that correlation explained by a direct 
effect of capital on future livelihood and a set of indirect effects of capital endowment on future livelihood through other assets or agency variables, such as child dependency ratios. Thus, it is possible to inspect the linkages between particular asset holdings and structural variables.

To achieve the decomposition, I follow a technique employed by Bowles and Gintis (2002), (see also Rao, et al., 1976; Cloninger, Rice and Reich, 1979; Otto, Feldman and Christiansen, 1994). In the language of Bowles and Gintis, the continuous measure of livelihood allows for a simple metric of persistence, based on the correlation between livelihood and all factors that go into its production. Moreover, these correlations may be decomposed into additive components reflecting the various causal mechanisms accounting for the persistence of poverty (Bowles and Gintis, 2002:5). As stated in Bowles and Gintis, "as long as the multiple regression coefficients are unbiased, the decomposition is valid whatever the relationship among the variables. Specifically, it does not require that the regressors be uncorrelated" (ibid: 9). This is a benefit to asset-based studies of poverty as it allows for an inspection into the household's asset bundle that is otherwise muddied by high estimated standard errors. The relatively high correlations between assets (such as land and livestock) will lead to less efficient estimates in an ordinary regression equation, but OLS is still the best linear unbiased estimator. Concurrently, one criticism levied on asset-based approaches mentioned in section two is the use of a narrow range of assets. Often studies will use the value of household durables or an index score as the only proxy for all assets. The method that follows has only the requirement of being unbiased and is less concerned with efficiency. Therefore, inclusion of multiple asset holdings is not only possible, but desirable.

Modeled after the heritability of traits literature, information on the marginal impact of assets and agency, along with their correlations, show how the path of endowments impact on 
future livelihood can be traced out. This process is much like how a geneticist might trace out the transfer of athletic ability from parent to offspring. In this analogy, direct effects are akin to genetic transfers (nature) and the indirect agency interactions are much like the interaction of the offspring's talent set free via its environment (nuture).

To draw out the additive components of the correlation decomposition (that is to say, the direct and indirect components) begin by estimating

$\ln L_{\text {it }}=\beta_{0}+\beta_{1} A_{\text {ijt-1 }}+\beta_{2} X_{\text {imt- } 1}+\beta_{3} Z_{\text {int }}+u_{\text {it }}$

where i subscripts the household, $\mathrm{t}$ subscripts the time period, $\mathrm{X}$ is a vector of $\mathrm{m}$ household agency and structural characteristics, $A$ is a vector of $\mathrm{j}$ assets held by the household, $\operatorname{lnL}$ is the $\log$ of economic livelihood, and $\mathrm{Z}$ a set of $\mathrm{n}$ controls. All variables are normalized to have a zero mean and unit variance. Equation (1) has its roots in the theoretical framework outlined in Carter and Barrett (2006). $\beta_{1}$ represents the direct marginal effect of the endowment of asset $j$ on the $\log$ of period t livelihood. Similarly, $\beta_{2}$ represents the direct marginal effect of period $t-1$ household agency variables on period t livelihood. To draw out the indirect effect of the endowment of asset $\mathrm{j}$ on period $\mathrm{t}$ livelihood through the household agency requires additional exploitation of equation (1).

As with Bowles and Gintis substituting the above expression for $\ln L_{i t}$ into the expectation $\mathrm{E}\left[\mathrm{A}_{\mathrm{ijt}-1}, \ln \mathrm{L}_{\mathrm{it}}\right]$, and noting that if two variables have zero mean and unit variance, the correlation between these variables is the expected value of their product, giving

$\mathrm{r}\left(\mathrm{A}_{\mathrm{ijt}-1}, \ln \mathrm{L}_{\mathrm{it}}\right)=\mathrm{E}\left[\mathrm{A}_{\mathrm{ijt}-1}, \ln \mathrm{L}_{\mathrm{it}}\right]=\mathrm{E}\left[\mathrm{A}_{\mathrm{ijt}-1}, \mathrm{~A}_{\mathrm{ikt}-1}\right]^{*} \beta_{1}+\mathrm{E}\left[\mathrm{A}_{\mathrm{ijt}-1}, \mathrm{X}_{\mathrm{imt}-1}\right]^{*} \beta_{2}$ 
where $r\left(\mathrm{~A}_{\mathrm{ijt}-1}, \ln \mathrm{L}_{\mathrm{it}}\right)$ is the correlation between asset endowments and current economic livelihood. Given the normalization, $\mathrm{E}\left[\mathrm{A}_{\mathrm{ijt}-1}, \mathrm{~A}_{\mathrm{ijt}-1}\right]=1$ and $\mathrm{E}\left[\mathrm{A}_{\mathrm{ijt}-1}, \mathrm{X}_{\mathrm{imt}-1}\right]=\mathrm{r}\left(\mathrm{A}_{\mathrm{ijt}-1}, \mathrm{X}_{\mathrm{imt}-1}\right)$ and assuming that the equation (1) estimates of $\beta_{1}$ and $\beta_{2}$ are unbiased, equation (2) then reduces to

$r\left(A_{i j t-1}, \ln L_{i t}\right)=r\left(A_{i j t-1}, A_{i k t-1}\right) * \beta_{1}+r\left(A_{i j t-1}, X_{i m t-1}\right) * \beta_{2}$

Equation (3) allows for inspection of each individual asset's interaction with the household agency variables as well as asset-to-asset interactions. The first term of equation (3), $\mathrm{r}\left(\mathrm{A}_{\mathrm{ijt}-1}, \mathrm{~A}_{\mathrm{ikt}-1}\right)^{*} \beta_{1}$, is the indirect association of endowments on current livelihood through other assets when asset $\mathrm{j}$ is not equal to asset $\mathrm{k}$. In other words, it is the proportion of the total correlation of asset $\mathrm{j}$ and livelihood that indirectly works through some other asset not equal to $\mathrm{j}$. If asset $\mathrm{j}$ is equal to asset $\mathrm{k}$ (implying a correlation of exactly one) then the term simply reduces down to $\beta_{1}$, which is the direct impact of asset $\mathrm{j}$ on livelihood. The second term, $r\left(\mathrm{~A}_{\mathrm{ijt}-1}, \mathrm{X}_{\mathrm{imt}-1}\right)$ * $\beta_{2}$, is the proportion of the total correlation of asset $\mathrm{j}$ and livelihood that indirectly works through the household agency vector. Equation (3) describes the decomposition process of the total correlation between asset endowments and future livelihood into direct and indirect components as illustrated in figure two. All of the elements of equation (3) are illustrated in the figure. Each asset endowment has a direct impact on livelihood represented by the solid arrows. Additionally, each asset is correlated with other assets in addition to the agency variables. The dashed arrows represent this correlation. It is the combination of direct effects of assets and their correlations that make up the total correlation between endowments and future livelihood.

[INSERT FIGURE 2 HERE] 
The correlation decomposition not only allows for a convenient breakdown of the association of asset endowments with livelihood, but also provides a suitable benchmark to compare the economic significance of the household agency effects with the asset combination effects. An introductory economics course stresses the mutually dependent - and economically significant - relationship between capital and labor, as well as other productive inputs into the production process. Thus, side-by-side, the size of the household agency effects can then be compared in a meaningful way to the benchmark asset combination effects from this correlation decomposition. Because the household agency and asset variables of equation (1) are expressed in common standard deviation units, this comparison can be made.

Of related interest is the emergence of Fuzzy Set Theory (FST) often used to construct or uncover the multiple dimensions of well-being (for applications relevant for capabilities see for example Zimmerman, 2010; Berenger and Verrdier-Chouchane, 2007; Martinetti, 2006; Betti et. al., 2005; Betti and Verma, 2004; Baliamoune-Lutz, 2004; Qizilbash, 2002; Baliamoune, 2000). FST provides a strict mathematical framework in which vague conceptual phenomena can be precisely and rigorously studied (Zimmerman, 2010: 318). In situations in which an outcome, such as well-being, is not of a clear dichotomous distinction (i.e. poor vs. non-poor or happy vs. unhappy), FST is used to describe the degree of membership of particular states of being. The use of FST is of potential interest to this type of study where the process of converting resources into well-being is under the microscope. With the methods of FST, one could inspect the intersections of different fuzzy sets (or dimensions of well-being) to analyze the overlaps between particular measures of assets and agencies in their contribution to one's state of wellbeing. Moreover, one could simply replace the dependent variable of equation (3) with an index constructed using FST to broaden the scope of the outcome variable. 
Although the use of FST would be favorable for this type of research question, the choice to use, $\mathrm{L}_{\mathrm{it}+1}$, an opulence measure of well-being, as the outcome for this study rather than as constructed by FST is primarily guided by the desire to expand upon, rather than replace, existing asset-based studies. The motivation is to provide a constructive critique of prior studies of poverty traps and poverty trap thresholds. In particular, the aim is to re-interpret prior treatments of intrinsic ability in an $\mathrm{HD} / \mathrm{C}$ inspired way. To that end, the choice was made to start from the assets framework outlined in section two and evolve toward a capabilities-aware application. The inclusion of a broader conceptualization of well-being and the methods of FST stand to expand the reach of this study but are left to extensions and further research.

\section{DATA}

The case of KwaZulu-Natal, South Africa is used from 1998 - 2004 for continuity with past studies, as well as for its central focus on asset redistribution policies in a post-Apartheid era. Asset and land redistribution discussions have formally been on the policy table in South Africa at least since the African National Congress' (ANC) Freedom Charter of 1955 (Johns and Davis Jr., 1991; Hirsch, 2005). In a post-Apartheid era, the knowledge about facilitations and constraints to household agency via the asset bundle is a necessity for social policy and asset effectiveness. This section outlines the KwaZulu-Natal Income Dynamics Study (KIDS), describes the logic behind construction of household agency variables, and presents descriptive statistics and their trends. Section five then presents the results of the model. 


\section{(a) Data: KwaZulu-Natal Income Dynamics Survey (KIDS)}

In 1993 the Southern Africa Labour and Development Research Unit spearheaded the first South African national household survey, the Project for Statistics on Living Standards and Development (PSLSD). In 1998 and 2004 KwaZulu-Natal province was resurveyed as a subsample of the national survey by a research consortium including the University of Natal, the University of Wisconsin, and the International Food Policy Research Institute; this sub sample is named the KwaZulu-Natal Income Dynamics Study (KIDS) (Carter and May, 2001; May et al., 1999; May et al., 2007).

Similar in its construction to the familiar Living Standards Measurement Surveys (LSMS) found in over 100 hundred developing countries, the KIDS survey consists of a household survey in 1993, 1998, and 2004. In both 1993 and 1998 a community questionnaire accompanies the household survey providing information on public perceptions of trust, violence, community wide shocks, as well as infrastructure and services. The survey contains 760 household dynasties that were identified and surveyed in all three waves. Of the 760 households, all are from the African or Indian population of the province. The original survey contained information on white households, but due to measurement issues and small numbers represented these were dropped. The originally nationally representative PSLSD study from 1993 became less than regionally representative in the form of KIDS. This limits the analysis by not allowing for generalizations of the results. However, the narrow nature of the sample does afford modest control over wider-economy influences.

What are important to this analysis are the components of the household survey on asset ownership, social capital, and time use. Unfortunately, while the 1998 and 2004 rounds of 
sampling contain the relatively comprehensive sections regarding assets, social networks, and other household specific variables, the original 1993 round contains relatively little. This imbalance in the 1993 data limits the focus solely on 1998 and 2004. For consistency with the established asset poverty literature the focus is on asset endowments' impact on current livelihood. That is to say, with data only available for two time periods (1998 and 2004), many of the benefits of the panel nature of the data fall out due to only one observation per household as the dependent variable is in period $\mathrm{t}$ and regressors are in period $\mathrm{t}-1$.

Though the short nature of the data prohibits the inclusion of fixed effects, the relatively narrow scope may benefit this study in a number of ways. By narrowing the study to one province within South Africa that includes only non-white households, differences in the available opportunity set outside of the household can more reasonably be assumed similar. Racial discrimination, for example, may largely be controlled for. All households in the study live in an environment with similar employment opportunities as shaped by the macroeconomic environment, save their geographic distance to urban centers, an issue easily addressed by the inclusion of a population density control.

\section{(b) Variables and Descriptive Statistics}

Tables one and two describe the data and correlations used in the decomposition. Economic livelihood, L, is the metric to capture welfare or utility. Following a similar method used in the livelihood mapping literature for South Africa in (Adato et. al 2006), it is defined as the total monthly expenditures per a household specific subsistence line, hsli. The subsistence line is simply the household size (in adult equivalent units) multiplied by the 1998 Rand 
equivalent of two dollars per day for 30 days. The livelihood mean of 2.26 poverty line units (PLUs) suggests the average household in the sample has an economic livelihood of 2.26 times the arbitrarily chosen poverty line.

[INSERT TABLE 1 AND TABLE 2 HERE]

\section{(i) Asset Holdings}

Assets themselves are multidimensional. As mentioned above, the use of an aggregated asset index limits the study's ability to address how particular assets act as a mechanism for agency variables to condition critical asset thresholds. To that end, five primary categories of assets are used: capital (K), educated labor (Le), uneducated labor (Lu), agricultural land (La), and unearned transfers $(\mathrm{T})$. Productive capital is reduced from seven dimensions down to one index, K. It is the first principle component (PCA) of: financial assets, household durables, electricity in the home (yes/no), number of rooms in the home, home ownership (yes/no), self employment equipment, and agricultural equipment. The PCA scores for K are conditional on each population density category ( $1=$ rural, $2=$ village/town, $3=$ urban) to capture the differences in relative values of particular assets across rural and urban areas. For example, farming equipment might be of greater significance in rural areas than in downtown Durban, a metropolitan area of more than two million people.

Agricultural land access, La, is used over land ownership due to the fact that very few respondents report owning any land, but many report having access. This reflects the tribal dynamics within the province. La is a categorical variable in which an individual has no access to either grazing or crop land $(\mathrm{La}=0)$, access to either grazing or crop land $(\mathrm{La}=1)$, or access to both (La=2). Between 1998 and 2004 urban and metropolitan households experienced a slight 
rise in access to agricultural land, whereas rural households experience a slight decline in land access.

Human capital is modeled as education embodied in labor, and is thus divided into educated versus uneducated labor. The number of educated or uneducated laborers in the home is used as these measures reflect of the overall situation in the household and aggregate more easily than do average years of educational attainment or education of the household head. As well, just focusing on education levels of parents ignores the potentially large impact that younger, more educated members may have on the household. The average household in KwaZulu-Natal has approximately twice as many uneducated workers as educated workers in the home. At the same time, all three population density groups experienced significant rises in the number of educated workers within the home between 1998 and 2004.

Unearned transfers reflect the average monthly value of transfer payments and remittances the household has had access to over the prior twelve months. The source of this income may come from members that have migrated out of the house and sent earnings back into the home or government programs such as the Old Age Pension Grant.

Of the five asset endowments, capital, land, and the two labor divisions are more highly correlated with future economic livelihood than the unearned transfers category. This low correlation between $\mathrm{T}_{\mathrm{t}-1}$ and $\mathrm{L}_{\mathrm{t}}$ is to be expected. The correlation would tend to be negative as lower income households are targeted for higher public transfers. However, if the programs are successful, those receiving transfers in 1998 would be expected to achieve higher livelihood in 2004 and lead to a positive correlation. 


\section{(ii) Household Agency Variables}

Perhaps of greater interest are variables that capture the essence of household agency or freedoms in the form of heterogeneous opportunity costs across households. When individuals face different time constraints within the family or community, it creates a varied set of costbenefit decisions across households with respect to adoption of new livelihood generating strategies. This study uses five variables describing the structure of the household: elderly dependency ratio (eDR), child dependency ratio (cDR), subsistence time deprivation (TMpc), associational activity (ASC), and trust in one's local network/community (TRST).

Using these five variables as proxies for household agency extends Carter and Ikegami's (2007) theoretical treatment of the determinants of poverty trap thresholds. In that simulation, the authors suggest that a latent concept of intrinsic ability conditions how high the minimum assets need to be in order to gravitate toward a higher welfare equilibrium. The lack of discussion of what intrinsic ability might encompass combined with the HD/C's criticisms that asset-based measures contain little discussion of factors that affect asset returns, elicits greater empirical study of intrinsic ability. Thinking in terms of capabilities, measures such as the dependency ratio and subsistence time deprivation potentially capture the inability of households to embrace new productive opportunities; that is to say, for households to be agents of their own change ${ }^{6}$. Bridging social capital has the potential to create additional productive alternatives that may not have otherwise existed. Bonding social capital can alleviate time deprivations, provide psychological and emotional support, and facilitate opportunities through the reduction of fear of harm. All five measures represent an aspect of agency, are empirically observable, and play an indirect role in the persistence or transition out of poverty. 
The dependency ratio is disaggregated to draw out the fundamentally different roles that non-working age household members play. An individual is of working age if they are between the ages of sixteen and sixty. Any member younger is considered to be a child dependent. Similarly, any member older than age sixty is considered to be an elderly dependent. The dependency ratio is calculated as the proportion of dependents to working age adults. The natural distinction between child and adult dependents implicitly centers on the role of in home care and contributions of resources (such as the Old Age Pension Grant or asset ownership). It is assumed that a high child dependency ratio will reflect a different set of opportunity costs of switching to out of the home employment than would a high elderly dependency ratio. The key question is if there are identifiable asset holdings in which the constraints become more binding.

The degree of time deprivation describes the amount of time the household spends in subsistence activities such as fetching water and gathering fuel wood. This is the per capita number of hours per week that the household spends in these activities. It is expressed in per capita terms to distinguish the effects of subsistence activities from any overlap with household size or dependency ratios.

In $1998,64 \%$ of the 744 households report spending some amount of time either gathering wood or fetching water. The median household spent approximately ten minutes per person over the week, whereas the $90^{\text {th }}$ percentile household spent two hours per person per week. In 2004, the median household reports an increase of only a few minutes, and the $90^{\text {th }}$ percentile reports a drop of twelve minutes per person. Immediate inspection of the median trends suggest that for KwaZulu-Natal, the degree of time deprivation arising from subsistence activities has only marginally improved for poorest households and appears to persist for the 
majority into 2004. However, a closer inspection of these trends with respect to population densities highlights the potential role of time deprivation as a capability constraint.

Between 1993 and 1998 the degree of time spent on subsistence activities has significantly declined for almost all rural households but leveled off from 1998 to 2004. During the latter time period the proportion of the 744 households living in rural areas falls from $42 \%$ to $40 \%$ presumably relocating to more populated areas in which the proportion rises by a similar magnitude. What is interesting to note is that the proportion of rural households reporting any time spent on subsistence activities rises from $88 \%$ to $94 \%$ while in urban areas the proportion falls over the same time period. This suggests that household with less subsistence constraints are more likely to move away from the rural areas. The resultant question then is: Do subsistence time commitments constrain rural households' ability to take on the opportunities presented in more populated areas or are there other dynamics governing these trends?

To further capture freedoms generated by household agency, social capital is treated as having an indirect influence on assets, rather than as an asset itself. Two measurable forms of social capital are used: bridging and bonding social capital. The former is measured as the number of different associations the household belongs to. Although this measure is blind to informal social identities, it is reasonably comprehensive in the KIDS survey and includes financial, religious, and other associations. Bonding social capital is measured by an index of trust in the local community. This is a self-reported rating (scale of one to five with higher equaling more trust) of how much one trusts their immediate family, extended family, neighbors, strangers, and local government. As with the construction of the capital asset, $\mathrm{K}$, this was reduced in dimensionality via principle component analysis. It is not clear that there is an income distinction between the two types of assets. An inspection of the KIDS sample suggests that 
neither form of social capital has a correlation with monthly income higher than .05 in absolute value. Again, the question of interest is whether an identifiable pattern exists in which social capital works through a particular asset holding to condition critical poverty trap thresholds.

\section{(iii) Additional Controls}

Additional control variables used in estimating equation one and three include the number of positive and negative financial surprises per capita that the household reports experiencing within the past two years and the variable labeled saver. This is a dummy equal to one if the change in $\mathrm{K}$ (primarily driven by financial capital and household durables) from one time period to the next is positive. Since the unbalanced nature of the data do not allow for fixed effects, this control is a modest proxy to capture the differing autonomous saving strategies across households (at least the outcome of those strategies). In addition, community negative shocks are reported from the community survey and are a count of the number of negative shocks the community has experienced over the past two years. Examples of negative community shocks are the death of a local leader, a health outbreak, or flood. In $1998,80 \%$ of KIDS respondents lived in a community in which negative shocks were reported on the community survey.

One particular dynamic characteristic of households is that they tend to expand and contract in response to life events over time. This change in size potentially creates measurement error due to, say, accumulation of a new spouse between 1998 and 2004. To account for possible measurement error of household dynasties, the change in household size is included. 


\section{RESULTS and DISCUSSION}

Decomposing the total correlation of asset endowments and current livelihood provides a novel way of looking into the household's black box of asset holdings to identify patterns and relationships between structural characteristics and particular asset holdings. Knowledge of how structural characteristics that lead to agency are linked to particular asset holdings results in a greater understanding of how households convert asset stocks into economic livelihood. Are households that are dependent on uneducated labor more bound by a lack of social network or time spent on subsistence activities when attempting to generate economic livelihood?

Tables two and three present the correlation coefficients and estimation results of equation (1), respectively. Together they create the decomposition of equation (3). Table four then presents the entire correlation decomposition, and figures three and four illustrate the decomposition components.

\section{[INSERT TABLE 3, TABLE 4, FIGURE 3, AND FIGURE 4 HERE]}

Recall the dependent variable is the log of economic livelihood calculated as total monthly expenditures per a household specific subsistence line. The latter subsistence line is primarily a function of household size and not observed budget shares of subsistence needs. The asset endowment coefficient is to be interpreted as the incremental percentage change in livelihood that a one unit increase in the asset endowment generates. If the coefficient is negative, such as the case of uneducated labor, it suggests that an additional uneducated laborer in the household may increase the future consumption, but not by enough to offset the increased subsistence needs of having the additional household member. Capital and educated labor have the expected signs. Agricultural land has a negative impact on economic livelihood. This is not 
an uncommon finding as prior labor market experiences may draw individuals toward agricultural land as a livelihood strategy. Although the negative sign on agricultural land illustrates interesting dynamics in the South African labor market it presents an additional challenge. The challenge is that the correlation decomposition requires the estimates from equation (1) to be unbiased. The negative sign on land may be indicative of endogeneity, and thus require interpretations to be made with a degree of caution. This challenge aside, the discussion now turns to identifying patterns among particular asset holdings and agency variables.

The identification and comparison of the indirect components identify three primary results. First, the indirect components of asset-to-asset complementarities and the household agency account for the lion's share of the total correlation. Second, the household agency components are on par with the magnitude of the asset-to-asset components. Lastly, as the black box of asset holdings is opened up, interesting associations between higher powered assets (capital, educated labor, and to some extent land) and time deprivations emerge. Further, land and uneducated labor exhibit strong associations. As will be discussed in greater detail below, these last patterns may be suggestive of the overriding role of macro-constraints to livelihood generation relative to micro-constraints.

As mentioned above, the indirect components of asset-to-asset complementarities and the household agency account for the lion's share of the total correlation. The decomposition results of table four show that the direct effects of asset endowments on future livelihood make up approximately forty percent of the total correlation for each of the different assets. ${ }^{7}$ The estimated correlation between educated labor endowment and future livelihood is .25 (compared to an actual correlation of .31). Of that total correlation, .10 is estimated as the direct impact of 
putting 1998 educated labor to use directly leading to higher livelihood levels in 2004 . An additional .1 of the total .25 correlation is estimated to be due to 1998 educated labor's impact on 2004 livelihood via it's associations with various agency or capability variables. The final additive correlation component of .05 is the estimated proportion of 1998 educated labor's impact on 2004 livelihood via other asset holdings. Concerning an asset-based model of poverty trap thresholds outlined in section two, the fact that indirect effects of asset endowments make up the lion's share of the correlation with future livelihood underscores the likelihood that critical asset thresholds are unique across households.

As figure three clearly shows, the impacts endowments have on future livelihood through household agency variables are at least as important as asset combination effects. Child and elderly dependency ratios, local community trust and networks, as well as, subsistence time deprivation all play a role in impacting welfare via asset holdings. This observation is integral to any argument of the relative economic importance of the household agency component. All variables are expressed in common standard deviation units due to the standardization process before estimating equation (1). This allows for direct comparison of the relative sizes to be made.

The last two categories of table four look more in depth to particular asset holdings and their associations with different agency variables. However, figure four provides a clearer picture of the relative size of the indirect components. On the vertical axis is the absolute value of the indirect correlation as a percent of the direct effect of a particular asset endowment. The horizontal axis is categorized by the indirect component and the shaded bar is the asset of interest. For example, the leftmost bar in the land group (fourth bar from the left) implies the indirect effect of 1998 capital endowments on 2004 livelihood through land is $27 \%$ of the size of 
the direct correlation component. ${ }^{8}$ Note that transfer assets are left out of figure four due to the relatively small interactions.

It is immediately evident from figure four that the impact that educated labor, land, and capital have on livelihood through subsistence time deprivation is larger than any of the other indirect components including any asset-to-asset complementarities. Though the asset-to-asset complementarities are not unimportant, one could interpret this as evidence of the economic significance of the indirect time poverty component. The fact that the subsistence time interaction is relatively larger attests to the importance of a deeper focus of poverty policy than simple asset redistributions. The answer to the question of how many assets is enough to ensure time is an ally of the poor is a complex one. The results here suggest that a household's ability to take on new economic opportunities may in part be a function of its subsistence commitments in the home.

Recall the observation of section four in which the proportion of the KIDS sample remaining in rural areas decreased at the same time that the proportion of households reporting some amount of time spent on subsistence activities was rising. The hypothesis was that perhaps only households with less subsistence demands were able to take on new opportunities in urban areas. The results of this section are indirect support that this hypothesis is at least plausible.

Returning to labor viewed as two fundamentally different assets, educated and uneducated, an interesting pattern emerges. Educated labor tends to be more heavily associated with subsistence time deprivation, but uneducated labor interacts with local community trust, capital, and land to a relatively larger degree. This reflects a pattern in which households dependent on uneducated labor are attached to agricultural production perhaps due to familial heritage, past labor market experiences, or simply a skills mismatch at the macroeconomic level. 
The two patterns of educated labor being associated with time deprivation and the association of uneducated labor and agricultural land may be reflective of the macroeconomic structure in South Africa. One interpretation of the patterns emerging from figure four is that the macroeconomic constraints of underemployment may be pressing down harder on lowerresourced households more so than the well-resourced households. Told another way, this could reflect the fact that the employment situation for most of South Africa is relatively bleak, but there exists enough employment opportunities for the more highly educated households. Further, this analysis is statistically identifying a subset of the well-resourced households that are more constrained by micro-level, household conditions. This interpretation would suggest that time deprivation may still be a future constraint for the less educated, but that larger, macroeconomic constraints are more likely the binding issue.

\section{(a) Macro and Micro Policy Implications}

The patterns that emerge from the correlation decomposition provide the first empirical description of the interaction between asset holdings and household agency. The results, however, are difficult to generalize beyond a sub-group in the KwaZulu-Natal province. The obvious limitation is from the sample not being nationally representative. Yet there is a bigger issue at play. As the above interpretation of labor and time deprivations illustrated, the wider economic situation shapes the interpretations of the decomposition. For the KIDS sample in South Africa, it appears that the degree of time deprivation conditions poverty trap thresholds more for those households with more education, capital and land. This may not be the case in an economic environment of full employment and robust growth where the opportunities for 
process switching are available to all asset holders. One could easily make the argument that the economy-wide phenomena play a significant role in the presence of under development.

In a response to prior asset-based studies of chronic poverty in KwaZulu-Natal, Aliber (2003) states, "that the emphasis...place(d) upon household assets as a determinant of structural poverty or non-poverty - even though 'assets' are understood broadly to include human capital, money, social claims, and other forms of wealth - appears to obscure the overriding importance of employment as a cause of poverty".

The conclusions from this study support Aliber's claim that the macroeconomic employment crisis in South Africa may in part separate households into transient and chronic poverty. However, the lack of statistical evidence of micro-capability constraints for lowresource households in this study does not necessarily suggest that they are less affected than high-resource households. Rather, the statistical evidence may be hidden by broad underemployment among low-resource groups. In the context of the chronic versus transitory poverty debate, the current analysis suggests that low-resource households are more likely to be chronically poor due to their low asset base, and that a subset of high-resource households that face agency constraints are also more likely to be chronically poor.

Thus, the results of this study suggest two dimensions of poverty policy that highlight that asset transfers alone are simply one of many means and not an end to poverty reduction. The first policy implication is that without a macroeconomic environment of more robust growth and employment opportunities, capital and land transfers may be ineffective due to a lack of viable outlets for those assets. Educated labor may be more insulated to the underemployment crisis simply due to the relative scarce supply of educated laborers. 
The second lesson for poverty policy and asset-based studies concerns the role of binding micro-constraints to household agency. It was found that even for well-resourced households there exist a subset in which time constraints impede the conversion process of educated labor, capital, and land into economic livelihoods. Thus, targeted policies should account not just for levels of asset stocks, but the personal and social environment in which those assets are being employed within.

\section{CONCLUDING REMARKS}

The choice of analysis at the household level has its costs and benefits. Data on asset holdings, consumption, and general time use are typically more available at this level of aggregation. However, some very important dynamics are hidden when the household is viewed from the outside. In this analysis, the degree of time deprivation stemming from subsistence activities emerged as an important influence on how households are able to convert asset holdings into livelihood. If, as is the case in many regions, the delegation of subsistence activities falls disproportionately on household members, then gender or individual deprivations are central issues to be explored. How intra-household decision regimes and the allocation of time spent on different activities impact the livelihood generation process are important questions to be taken on next. Further, the nature and uses of agricultural land and crop production have important gender implications as well. This study does not address the uses of agricultural land, but differences in subsistence versus cash crop production may result in starkly different outcomes for men and women. Future research on asset holdings in conjunction with household agency should aim for explicit inclusion of the intra- and extra-household dynamics over time 
and regions. As well, broadening the scope of well-being beyond livelihood (opulence) would be beneficial in many regards.

On one level, this study is an attempt to bridge the asset-based and human development/capabilities perspectives of poverty measurement. The principal means to illustrate the potential of this hybrid perspective was to empirically draw out the fundamental relationship between a household's degree of agency and particular asset holdings. The results suggest that although asset-to-asset interactions are important, the degree of time deprivation from subsistence activities may condition poverty trap thresholds for households with higher levels of educated laborers, capital, and access to agricultural land. This statistical result may reflect the larger realities of macroeconomic underemployment in South Africa in which the relatively wellresourced groups have the wherewithal to face binding micro-constraints, whereas the lowresourced groups are primarily constrained by poor macroeconomic conditions. Poverty reduction strategies should not pull up short with a focus on asset accumulation levels alone. It was shown rather that the institutional setting at the macroeconomic and microeconomic level impact a households ability to convert a variety of asset holdings into economic livelihood. 


\section{REFERENCES}

Adato, M., Carter, M., \& May, J. (2006). Exploring Poverty Traps and Social Exclusion in South Africa Using qualititative and Quantititative Data. Journal of Development Studies 42, 226-247.

Aliber, M. (2003). Chronic Poverty in South Africa: Incidence, Causes and Policies. World Development 31, 473-490.

Alkire, S., \& Deneulin, S. (2009). A Normative Framework for Development. In S. Deneulin, \& L. Shahani (Eds.) An Introduction to the Human Development and Capability Approach (pp. 3-21). London, UK: Earthscan.

Antman, F., \& McKenzie, D. (2005). Poverty Traps and Nonlinear Income Dynamics with Measurement Error and Individual Heterogeneity. World Bank Policy Research Working Paper no. 3664.

Baliamoune, M. (2000). Economics of Summitry: An Empirical Assessment of the Economics of Summits. Empirica 27, 295-314.

Baliamoune-Lutz, M. (2004) On the Measurement of Human Well-Being. WIDER Research Paper No. 2004/16,

Banerejee, A., \& Newman, A. (1993). Occupational Choice and the Process of Development.

The Journal of Political Economy 101, 274-298.

Barrett, C. (2006). Fractal Poverty Traps. World Developmet 34 (1), 1-15.

Barrett, C. (2008). Poverty Traps and Resource Dynamics in Smallholder Agrarian Systems. In Rob B. Dellink and Arjan Ruijs (eds.), Economics of Poverty, Environment and NaturalResource use: Springer Science+Business Media B.V. 
Barrett, C., Marenya, P., McPeak, J., Mude, A., Vanderpuye-Orgle, J. \& Yirbecho, A. (2006). Welfare Dynamics in Rural Kenya and Madagascar. Journal of Development Studies 42, 248-277.

Berenger, V., \& Verdier-Chouchane, A. (2007) Multidimensional Measures of Well-Being: Standard of Living and Quality of Life Across Countries. World Development 35 (7), $1259-1276$.

Betti, G., \& Verma, V. (2004). A Methodology for the Study of Multi-Dimensional and Longitudinal Aspects of Poverty and Deprivation. Invited Paper, IAOS-IASS Joint Conference, Amman-Jordan.

Betti, G., Cheli, B., Lemmi, A., \& Verma, V. (2005). On the Construction of Fuzzy Measures for the Analysis of Poverty and Social Exclusion. In International Conference to Honour Two Eminent Social Scientists C. Gini and M. Lorenz, University of Siena.

Bowles, S \& Gintis, H. (2002). The Inheritance of Inequality. The Journal of Economic Perspectives 16, 3-30.

Carter, M., \& Barrett, C. (2006). The Economics of Poverty Traps and Persistent Poverty: An Asset-Based Approach. Journal of Development Studies 42, 178-199.

Carter, M., \& Ikegami, M. (2007). Looking Forward: theory-based measures of chronic poverty and vulnerability. CPRC Working Paper No.94.

Carter, M. \& May, J. (1999). Poverty, Livelihood, and Class in Rural South Africa. World Development 27, 1-20.

Carter, M. \& May, J. (2001). One Kind of Freedom: Poverty Dynamics in Post Apartheid South Africa. World Development 29, 1987-2006. 
Clark, D. (2005). Sen's Capability Approach and the Many Spaces of Human Well-Being. The Journal of Development Studies 41 (8), 1339-1368.

Cloninger, C. R., Rice, J., \& Reich, T. (1979). Multifactorial Inheritance with Cultural Transmission and Assortive Mating. II. A General Moeld of Combined Polygenic and Cultural Inheritance. American Journal of Human Genetics 29, 176-198.

Foster, J. E., Greer, J., \& Thorbecke, E. (1984). A Class of Decomposable Poverty Measures. Econometrica 52, 761-776.

Galor, O., \& Zeira, J. (1993). Income Distribution and Macroeconomics. Review of Economic Studies 60, 35-52.

Hirsch, A. (2005). Season of Hope: Econonomic Reform under Mandela and Mbeki.

Pietermaritzburg: Unversity of KwaZulu-Natal Press \& International Development Research Centre (IDRC).

Hulme, D., \& McKay, A. (2007). Identifying and Measuring Chronic Poverty: Beyond Monetary Measures. Chronic Poverty Research Centre - Indian Institute of Public Administration Working Paper 30.

Jalan, J., \& Ravallion, M. (2000). Is transient poverty different? Evidence for rural China. Journal of Development Studies 36, 82-99.

Johns, S., \& Davis Jr., R.H., (eds.) (1991). Mandela, Tambo, and the African National Congress: The Struggle against Apartheid 1949-1990: A Documentary Survey. New York: Oxford University Press.

Klasen, S. (2000). Measuring Poverty and Deprivation in South Africa. Review of Income and Wealth 46, 33-58. 
Lerman, R., \& McKernan, S.-M. (2008). The Effects of Holding Assets on Social and Economic Outcomes of Families: A Review of Theory and Evidence. Available at http://aspe.hhs.gov/hsp/07/PoorFinances/Effects/report.pdf, accessed February 2012.

Lokshin, M., \& Ravallion, M. (2004). Household Income Dynamics in Two Transition Economies. Studies in Nonlinear Dynamics and Econometrics 8.

Loury, G. (1981). Intergenerational Transfers and the Distribution of Earnings. Econometrica 49, 843-867.

Lybbert, T., Barrett, C., Desta, S., \& Coppock, D.L. (2004). Stochastic wealth dynamics and risk management among a poor population. Economic Journal 114, 750-777.

Martinetti, E.C. (2006). Complexity and Vagueness in the Capability Approach: Strengths or Weaknesses?. In F. Comim, M. Qizilbash, \& S. Alkire (Eds.), The Capability Approach: Concepts, Measures, and Applications (pp. 268-309). Cambridge, UK: Cambridge University Press.

May, J., Aguero, J., Carter, M., \& Ian M. Timaeus (2007). The KwaZulu-Natal Income Dynamics Study (KIDS) third wave: Methods, First Findings and an Agenda for Future Research. Development Southern Africa 24, 629-648.

May, J., Carter, M., Haddad, L., \& Maluccio, J. (1999). KwaZulu-Natal Income Dynamics Study (KIDS) 1993 -1998: A Longitudinal Data Set for South African Policy Analysis. CSDS Working Paper no. 21 Durban: Centre for Social and Development Studies. McKenzie, D., \& Woodruff, C. (2003). Do entry costs provide an empirical basis for poverty traps? Evidence from Mexican microenterprises. BREAD Working Paper No. 020. Mookherjee, D., \& Ray, D. (2002). Contractual Structure and Wealth Accumulation. The American Economic Review 92, 818-849. 
Nambiar, S. (2011). Capabilities and Constraints. Forum for Social Economics 40 (2), 179-195.

Otto, S., Feldman, M., \& Christiansen, F. (1994). Genetic and Cultural Transmission of Continuous Traits. Stanford University, Morrison Institute Working Paper No. 64.

Robeyns, I. (2007). The Capability Approach: a theoretical survey. Journal of Human Development and Capabilities 6 (1), 93-117

Qizilbash, M. (2002). A Note on the Measurement of Poverty and Vulnerability in the South African Context. Journal of International Development, 14 (3), 757-772

Qizilbash, M., \& Clark, D. (2005). The Capability Approach and Fuzzy Poverty Measures: An Application to the South African Context Social Indicators Research 74, 103-139.

Rao, D. C., Morton, N. E., \& Yee, S. (1976). Resolution of Cultural and Biological Inheritance by Path Analysis. American Journal of Human Genetics 28, 228-242.

Santos, P., \& Barrett, C. (2006). Heterogeneous wealth dynamics: On the roles of risk and ability. Cornell University Working Paper. Ithaca: Cornell University.

Sen. A. (1997). Editorial: Human Capital and Human Capability. World Development 25 (12), 1959-1961.

Sen, A. (1999a). Development as Freedom. Oxford: Oxford University Press.

Sen, A. (1999b). Commodities and Capabilities. Oxford: Oxford University Press.

Zadeh, L.A. (1965) Fuzzy Sets. Information and Control 8, 338-353.

Zimmermann, H. - J. (2010). Fuzzy Set Theory. Wiley Interdisciplinary Reviews: Computational Statistics 2 (3), 317-332. 


\section{NOTES}

${ }^{1}$ Author's calculations using the KwaZulu-Income Dynamics Study described in section four.

${ }^{2}$ The concept of well-being, assets, agency, livelihood, and resources are often ambiguous in nature. For purposes of consistency with prior asset-based studies, livelihood is a consumption measure of well-being. In this study, it is measured as the total monthly expenditures of the household relative to the household's poverty line. There is much more to be said on the conceptualization and analysis of well-being in sections 2,3 , and 4 .

${ }^{3}$ The terms critical thresholds and poverty trap thresholds are used interchangeably.

${ }^{4}$ Of the above authors, Santos and Barrett provide the most significant exception by addressing the role of herder ability when there is primarily one asset and livelihood strategy. They extend the work of Lybbert et al (2004) and empirically suggest that the minimum herd size where future accumulation behavior bifurcates is in part a function of herder ability as captured by past responses to shocks to herd size.

${ }^{5}$ See Klasen (2000), Qizilbash and Clark (2005), and Hulme and McKay (2007) for examples and comparisons of participatory and non-participatory measures of poverty.

${ }^{6}$ Of course having child dependents should not exclusively be seen as a facilitation or constraint to agency. To reiterate the comments of section 2.3 , the line between resources, agency, functionings, and capabilities is often a blurry one.

${ }^{7}$ The one exception is that unearned transfer assets' direct component accounts for sixty seven percent of its total, though the entire actual correlation is only .03. The indirect effects are exclusively through other assets rather than household agency characteristics.

${ }^{8}$ With respect to the data in table four, it is calculated as .03 divided by .11 . 


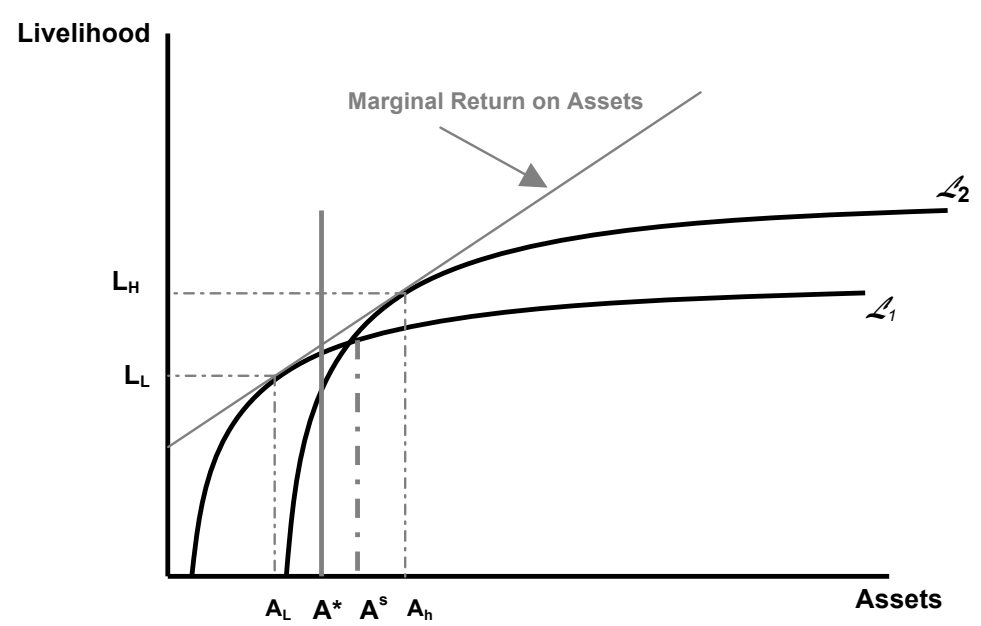

Figure 1: Multiple Equilibria 


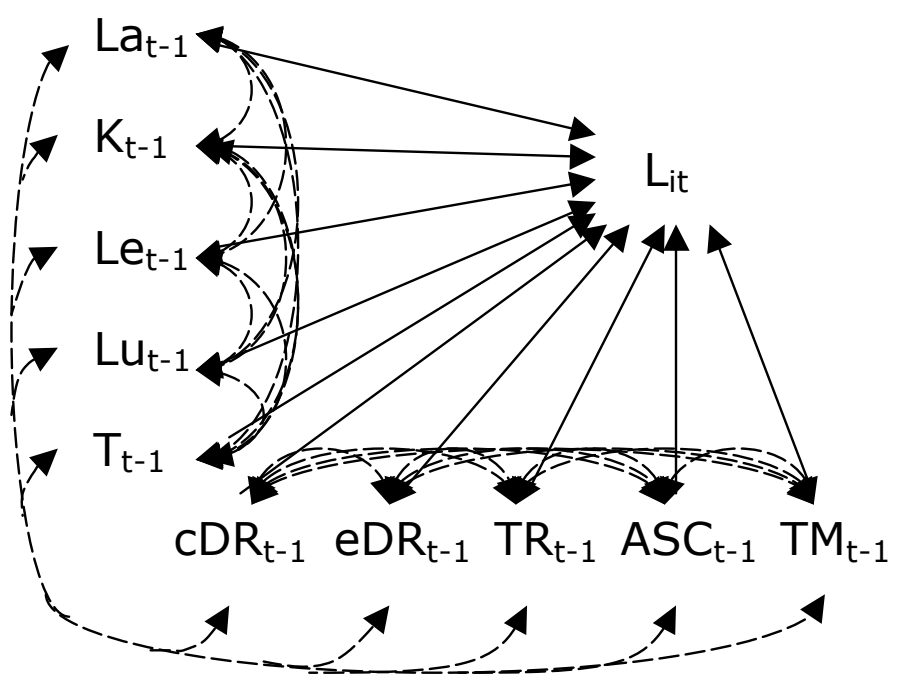

Figure 2: The Direct and Indirect Components of the Livelihood Conversion Process 


\section{Table 1: Variable Names and Descriptive Statistics}

\begin{tabular}{|c|c|c|c|c|c|}
\hline & $n=744$ & 1998 & & 2004 & \\
\hline Variable* & $\begin{array}{l}\text { Description }{ }^{* *} \\
\text { livelihood: total monthly expenditures }\end{array}$ & $\overline{\text { mean }}$ & (s.d.) & $\overline{\text { mean }}$ & (s.d.) \\
\hline $\mathrm{L}_{\text {it }}$ & $\begin{array}{l}\text { per a household specific subsistance } \\
\text { line }\end{array}$ & 2.26 & (3.36) & 3.47 & $(5.04)$ \\
\hline Inc & $\begin{array}{l}\text { Total Monthly Household Income in } \\
1998 \text { Rand. }\end{array}$ & 539.0 & $(1040.1)$ & 815.5 & (1710.5) \\
\hline $\mathrm{K}_{\mathrm{it}}$ & $\begin{array}{l}\text { Productive capital. Index derived from } \\
\text { durables, fin. assets, \# of rooms, agric. } \\
\text { equip, electricity in home, own vs rent, } \\
\text { home size, livestock. (normalized to } \\
\text { zero mean / unit var.) } \\
\text { Access to Agricultural Land. } 0=\text { no }\end{array}$ & 0 & $(1.37)$ & 0 & $(1.50)$ \\
\hline $\mathrm{La}_{\mathrm{it}}$ & $\begin{array}{l}\text { access, } 1=\text { access to either grazing or } \\
\text { crop, } 2=\text { access to both grazing and } \\
\text { crop land }\end{array}$ & 0.69 & $(0.76)$ & 0.91 & $(0.51)$ \\
\hline $\mathrm{Le}_{i t}$ & $\begin{array}{l}\text { \# of core members in } \mathrm{HH} \text { with more } \\
\text { than standard } 9 \text { education }\end{array}$ & 1.01 & (1.28) & 1.77 & (2.14) \\
\hline $\mathrm{Lu}_{\mathrm{it}}$ & $\begin{array}{l}\text { \# of core members in } \mathrm{HH} \text { with less than } \\
\text { standard } 10 \text { education }\end{array}$ & 3.9 & $(2.57)$ & 4.17 & (3.37) \\
\hline $\mathrm{T}_{\text {it }}$ & $\begin{array}{l}\text { Unearned income such as remittances } \\
\text { and transfers (adult equivalent) }\end{array}$ & 569.3 & (2806.19) & 876.72 & $(2673.35)$ \\
\hline $\mathrm{TMpc}_{\text {it }}$ & $\begin{array}{l}\text { Time poverty: \# of hours per week } \\
\text { spent gathering wood and water per } \\
\text { household member }\end{array}$ & 0.72 & (1.67) & 0.64 & (1.05) \\
\hline $\mathrm{cDR}_{\text {it }}$ & $\begin{array}{l}\text { Dependency ratio: \# of children per } \\
\text { working age adults (>60 years). }\end{array}$ & .66 & $(.52)$ & 1.32 & $(1.32)$ \\
\hline $\mathrm{eDR}_{\text {it }}$ & $\begin{array}{l}\text { Dependency ratio: \# of elderly per } \\
\text { working age adults (<16 years). }\end{array}$ & .12 & $(.20)$ & .14 & $(.25)$ \\
\hline $\mathrm{ASC}_{\text {it }}$ & $\begin{array}{l}\text { \# of different associations } \mathrm{HH} \text { belongs } \\
\text { to }\end{array}$ & 1.40 & (1.26) & 1.12 & $(1.30)$ \\
\hline TRST $_{\text {it }}$ & $\begin{array}{l}\text { Local Level Trust: 1st Principle } \\
\text { component of self-assessed level of } \\
\text { trust in family, extended family, } \\
\text { strangers, neighbors, and locol gov't. } \\
\text { Community Level Negative Shocks: \# in }\end{array}$ & 4.30 & (1.48) & 4.37 & $(1.46)$ \\
\hline $\mathrm{CN}_{\text {it }}$ & $\begin{array}{l}\text { past two years, community level, } \\
\text { reported by community survey e.g. } \\
\text { floods, outbreaks, etc. } \\
\text { dummy to capture household }\end{array}$ & 1.66 & $(1.47)$ & NA & NA \\
\hline saver $_{\text {it }}$ & $\begin{array}{l}\text { differences in consumption } \\
\text { propensities. } 1 \text { if change in } \mathrm{K} \text { from } 98- \\
04>0\end{array}$ & 0.36 & $(0.48)$ & 0.73 & $(0.45)$ \\
\hline popden it $_{\text {it }}$ & $\begin{array}{l}\text { population density. } 1=\text { rural, } \\
2=\text { village/town, } 3=\text { urban } \\
\text { \# of positive financial surprises reported }\end{array}$ & 2.00 & $(0.91)$ & 2.03 & $(0.91)$ \\
\hline $\mathrm{pSrp}_{\text {it }}$ & $\begin{array}{l}\text { by the } \mathrm{HH} \text { in the past two years per } \\
\text { household member }\end{array}$ & 0.17 & $(0.41)$ & 0.73 & $(0.86)$ \\
\hline $\mathrm{nSrp}_{\text {it }}$ & $\begin{array}{l}\text { \# of negative financial surprises } \\
\text { reported by the } \mathrm{HH} \text { in the past two } \\
\text { years per household member } \\
\text { household subsistence line: monthly }\end{array}$ & 0.53 & $(0.80)$ & 0.61 & $(0.87)$ \\
\hline hsli $_{\text {it }}$ & $\begin{array}{l}\text { equivelant of } \$ 2 \text { per day per } \mathrm{HH} \\
\text { member (adult equivelant in Rand) }\end{array}$ & 1421.4 & $(860.6)$ & 1686.3 & (1058.5) \\
\hline
\end{tabular}




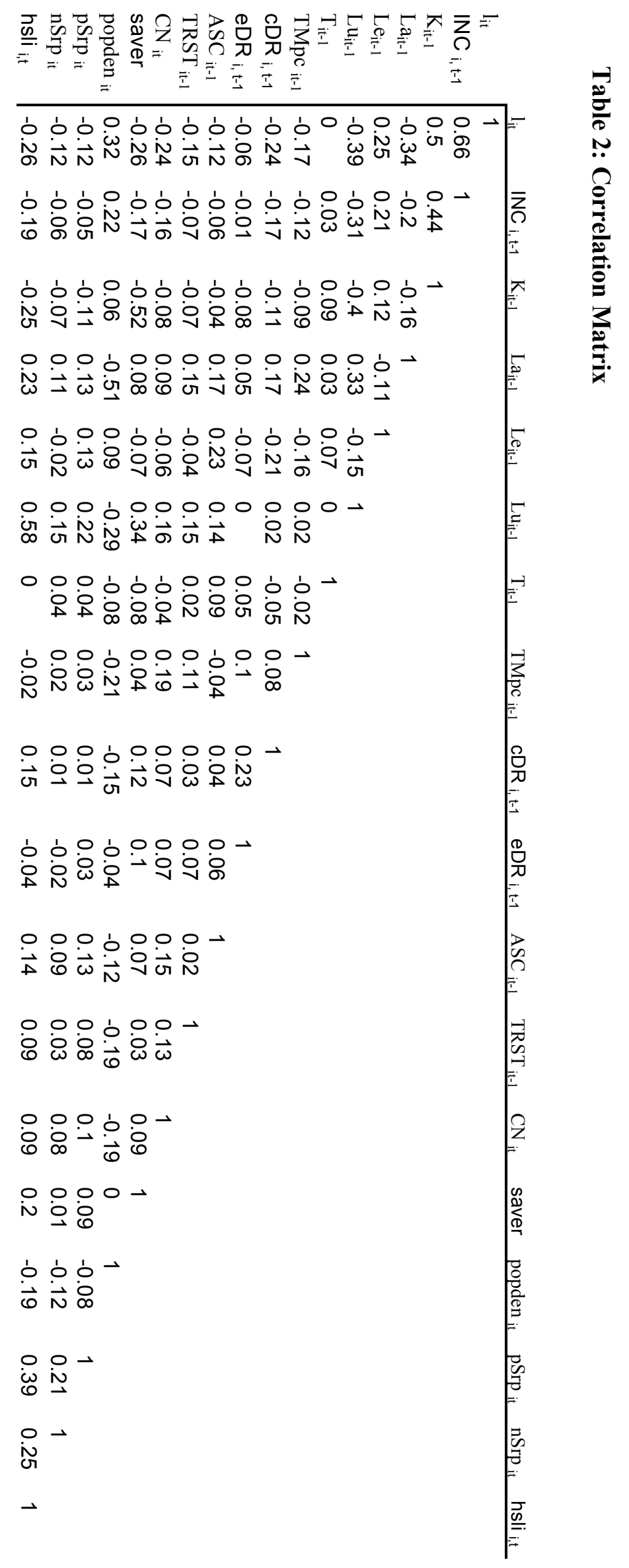




\section{Table 3: Structure and Asset Endowment on Livelihood}

\begin{tabular}{|c|c|c|c|}
\hline \multicolumn{2}{|c|}{ (i) Asset Endowments } & \multicolumn{2}{|l|}{ (ii) Household Structure and Agency } \\
\hline $\mathrm{K}_{98}$ & $\begin{array}{l}0.11^{* * *} \\
(0.04)\end{array}$ & $\mathrm{TMpc}_{98}$ & $\begin{array}{l}-0.41^{* *} \\
(0.19)\end{array}$ \\
\hline $\mathrm{La}_{98}$ & $\begin{array}{l}-0.17^{* * *} \\
(0.04)\end{array}$ & $\mathrm{cDR}_{98}$ & $\begin{array}{l}-0.11^{* *} \\
(0.05)\end{array}$ \\
\hline Le 98 & $\begin{array}{l}0.10^{* * *} \\
(0.03)\end{array}$ & $\mathrm{eDR}_{98}$ & $\begin{array}{l}0.02 \\
(0.03)\end{array}$ \\
\hline $\mathrm{Lu}_{98}$ & $\begin{array}{l}-0.12^{* * *} \\
(0.04)\end{array}$ & $\mathrm{ASC}_{98}$ & $\begin{array}{l}0.04 \\
(0.03)\end{array}$ \\
\hline $\mathrm{T}_{98}$ & $\begin{array}{l}-0.02 \\
(0.02)\end{array}$ & TRST $_{98}$ & $\begin{array}{l}-0.19^{* * *} \\
(0.03)\end{array}$ \\
\hline \multicolumn{2}{|c|}{ (iii) Endowment Changes } & (iv) Structural Change & \\
\hline$\Delta \mathrm{K}_{98}$ & $\begin{array}{l}0.03 \\
(0.02)\end{array}$ & $\Delta \mathrm{TMpc}_{98}$ & $\begin{array}{l}-0.02 \\
(0.02)\end{array}$ \\
\hline$\Delta \mathrm{La}_{98}$ & $\begin{array}{l}-0.12^{* * *} \\
(0.04)\end{array}$ & $\Delta \mathrm{cDR}_{98}$ & $\begin{array}{l}-0.04^{*} \\
(0.02)\end{array}$ \\
\hline$\Delta \operatorname{Le}_{98}$ & $\begin{array}{l}0.05^{\star * *} \\
(0.02)\end{array}$ & $\Delta \mathrm{eDR}_{98}$ & $\begin{array}{l}0.04 \\
(0.09)\end{array}$ \\
\hline$\Delta \mathrm{Lu} 98$ & $\begin{array}{l}-0.01 \\
(0.02)\end{array}$ & $\Delta \mathrm{ASC}_{98}$ & $\begin{array}{l}0.03^{*} \\
(0.02)\end{array}$ \\
\hline$\Delta \mathrm{T}_{98}$ & $\begin{array}{l}-0.00 \\
(0.00)\end{array}$ & $\Delta \mathrm{TRST}_{98}$ & $\begin{array}{l}-0.12^{* * *} \\
(0.02)\end{array}$ \\
\hline \multicolumn{4}{|c|}{ (v) Other Explanatory Variables } \\
\hline $\mathrm{CN}_{98}$ & $\begin{array}{l}-0.04^{*} \\
(0.02)\end{array}$ & & \\
\hline $\operatorname{lnINC} 04$ & $\begin{array}{l}0.46^{* * *} \\
(0.03)\end{array}$ & $\mathrm{N}$ & 730 \\
\hline popden $_{04}$ & $\begin{array}{l}0.11^{* * *} \\
(0.03)\end{array}$ & R-squared & 0.72 \\
\hline pSrp 98-04 & $\begin{array}{l}-0.45^{\star *} \\
(0.21)\end{array}$ & Robust standard errors in parentheses & \\
\hline nSrp $98-04$ & $\begin{array}{l}0.11 \\
(0.22)\end{array}$ & $\begin{array}{l}\text { Note: Variables normalized to have zero mean and unit variance. } \\
{ }^{* * *} p<0.01,{ }^{* *} p<0.05,{ }^{*} p<0.1\end{array}$ & \\
\hline dhhsize $_{98-04}$ & $\begin{array}{l}-0.01 \\
(0.01)\end{array}$ & & \\
\hline Constant & $\begin{array}{l}-2.78^{* * *} \\
(0.19)\end{array}$ & & \\
\hline
\end{tabular}


Table 4: Decomposition of the Correlation Between 1998 Asset

Endowments and 2004 Livelihood

$\mathrm{N}=730$

Total Est. vs Actual Correlation

\begin{tabular}{lll} 
& Est. & Act. \\
\cline { 2 - 3 } $\mathrm{K}$ & 0.29 & 0.42 \\
$\mathrm{Le}$ & 0.25 & 0.31 \\
$\mathrm{Lu}$ & -0.3 & -0.47 \\
$\mathrm{La}$ & -0.41 & -0.42 \\
$\mathrm{~T}$ & 0.00 & 0.03
\end{tabular}

Direct Association of $A_{j, t-1}$ and $\ln L_{t}$ Direct Impact

K $\quad 0.11$

Le $\quad 0.1$

Lu $\quad-0.12$

La $\quad-0.17$

$\begin{array}{ll}\mathrm{T} & -0.02\end{array}$

Ind. Assoc. of $A_{j, t-1}$ and $I n L_{t}$ through Agency Variables

\begin{tabular}{llllll} 
& eDR & CDR & TMpc & ASC & TRST \\
\cline { 2 - 6 } $\mathrm{K}$ & 0.00 & 0.02 & 0.05 & 0 & 0.02 \\
$\mathrm{Le}$ & 0.00 & 0.01 & 0.08 & 0.01 & 0.00 \\
$\mathrm{Lu}$ & 0.00 & -0.01 & -0.04 & 0.01 & -0.02 \\
$\mathrm{La}$ & 0.00 & -0.02 & -0.13 & 0.01 & -0.02 \\
$\mathrm{~T}$ & 0.00 & 0.00 & 0.00 & 0.00 & 0.00
\end{tabular}

Ind. Assoc. of $A_{j t-1}$ and $\ln L_{t}$ through Other Assets

K

\begin{tabular}{lllll} 
K & Le & Lu & La & T \\
\hline -NA- & 0.01 & 0.05 & 0.03 & 0.00 \\
0.01 & -NA- & 0.02 & 0.02 & 0.00 \\
-0.05 & -0.01 & $-N A-$ & -0.06 & 0.00 \\
-0.02 & -0.01 & -0.04 & $-N A-$ & 0.00 \\
0.01 & 0.01 & 0.00 & -0.01 & $-N A-$
\end{tabular}




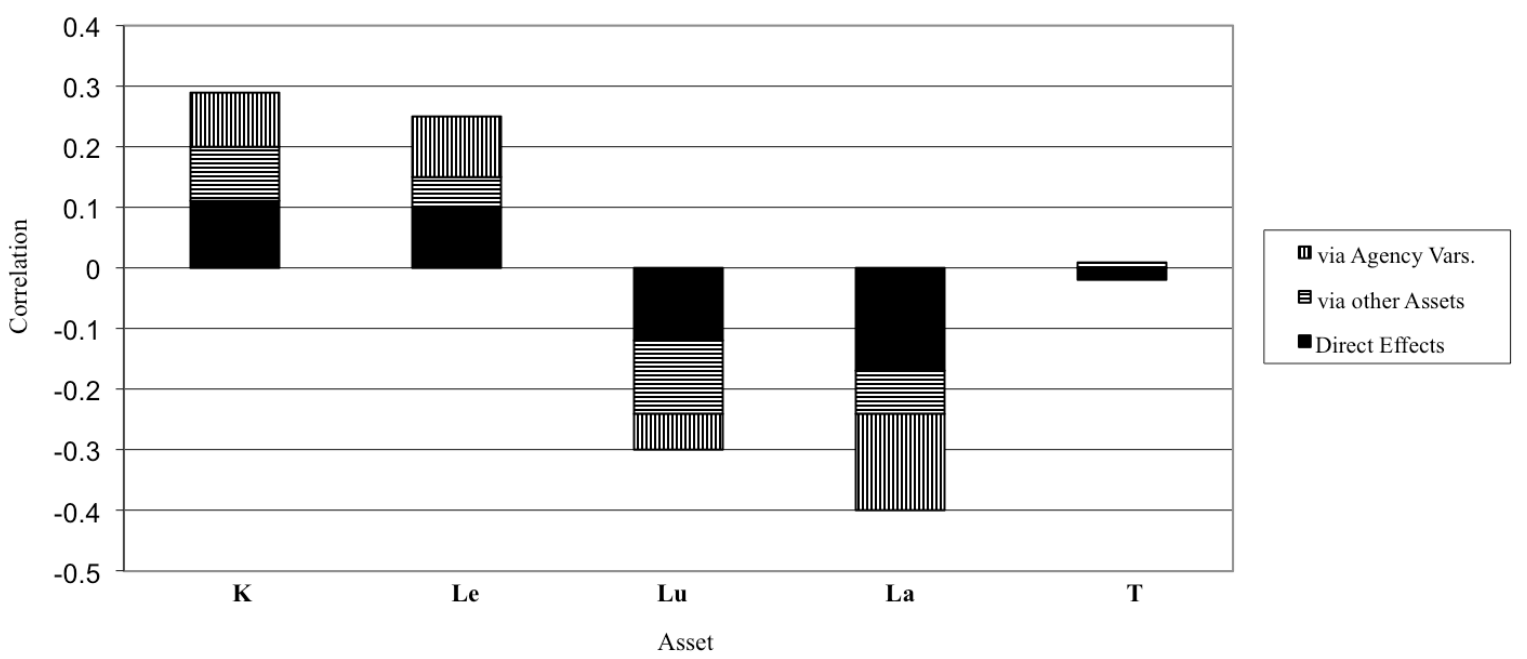

Figure 3: Correlation Decomposition of Asset Endowments and Current Livelihood into Direct and Indirect Effects 


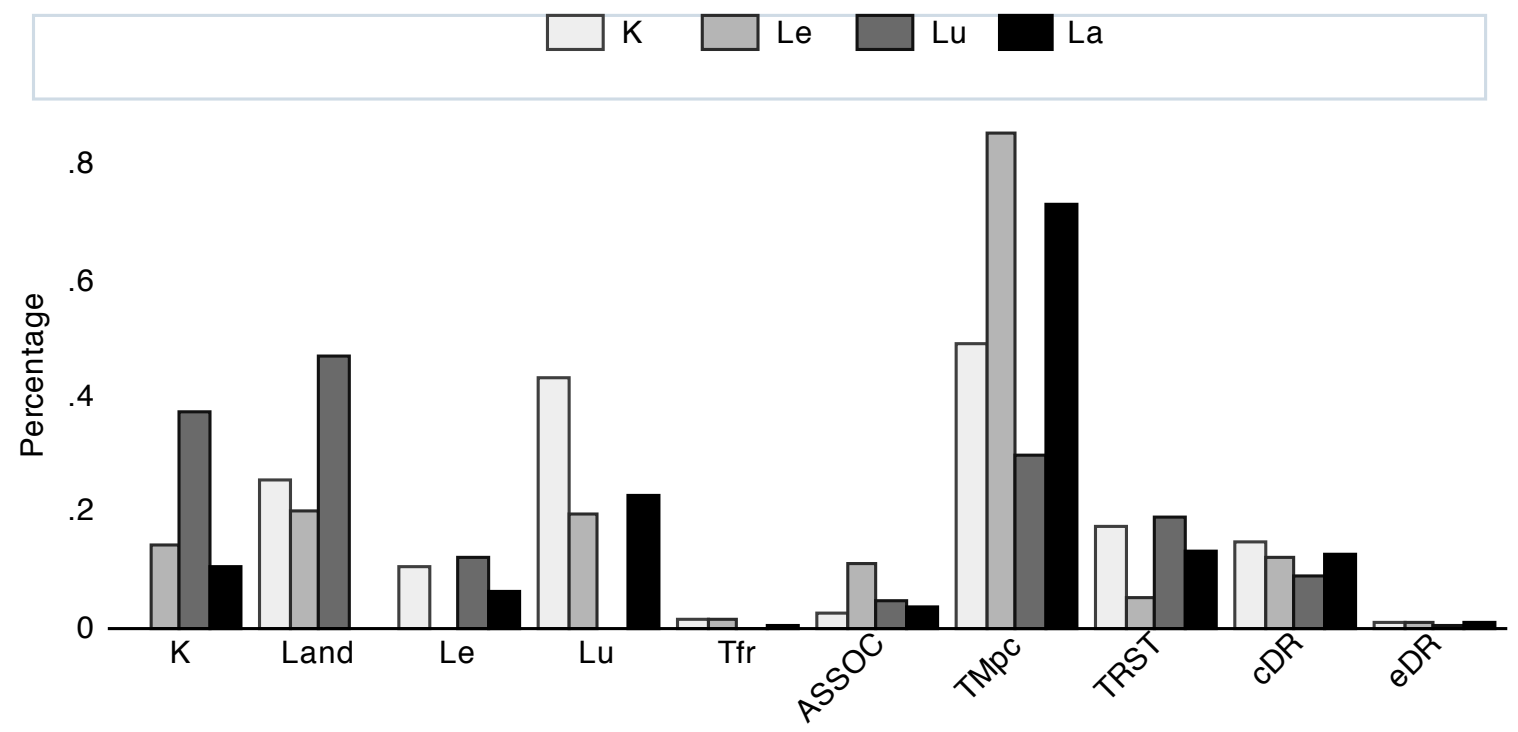

Where asset $\mathrm{j}$ is not equal to asset $\mathrm{k}$.

Figure 4: Simultaneous Interaction of Agency and Assets

Indirect Correlation Component as a Percent of Direct Correlation Component (Absolute Value) 